\title{
Nutritional, chemical and bioactive profiles of different parts of a Portuguese common fig (Ficus carica L.) variety
}

\author{
Luís Palmeira, Carla Pereira, Maria Inês Dias, Rui M.V. Abreu, Rúbia C.G. Corrêa, \\ Tânia C.S.P. Pires, Maria José Alves, Lillian Barros*, Isabel C.F.R. Ferreira* \\ Centro de Investigação de Montanha (CIMO), Instituto Politécnico de Bragança, Campus de Santa Apolónia, 5300-253 Bragança, Portugal
}

\section{A R T I C L E I N F O}

\section{Keywords:}

Ficus carica L.

Peel

Pulp

Industrial by-product

Phenolic composition

Antioxidant capacity

Cell-based antioxidant methods

Antibacterial potential

\begin{abstract}
A B S T R A C T
This study aims to give an unprecedented contribution on the chemical composition and bioactivities of the most produced and appreciated Portuguese fig variety ("Pingo de Mel") with the view of expanding the knowledge on its potentialities. An advanced characterization of its peel and pulp parts was carried out. Four free sugars (glucose, fructose, trehalose and sucrose), 5 organic acids (oxalic, quinic, malic, citric, and succinic acids), tocopherols in all their 4 forms, besides 23 fatty acids were detected in the samples. Fifteen different phenolic components were found in the peel hydroethanolic extract; whereas 12 were detected in the pulp hydroethanolic extract. Quercetin-3-O-rutinoside (rutin) was the major constituent of the peel, accounting for $33.8 \%$ of its phenolic content, followed by 5-O-caffeoylquinic acid and vanillic acid malonyl di-deoxyhexoside. Caffeic acid derivatives, such as caffeic acid hexosides, were the major components of pulp, followed by vanillic acid derivatives and $O$-caffeoylquinic acid. Both extracts displayed promising antioxidant capacities in all methods used, namely the 2,2-diphenyl-1-picrylhydrazyl radical-scavenging, the reducing power, the inhibition of $\beta$-carotene bleaching assays, the thiobarbituric acid reactive substances assay and the oxidative haemolysis inhibition assay; however, the peel presented significantly lower $\mathrm{IC}_{50}$ values than pulp. The extracts showed practically identical antibacterial capacities, being effective against methicillin-sensitive Staphylococcus aureus (MICs $=2.5 \mathrm{mg} / \mathrm{mL}$ ), besides methicillin-resistant $S$. aureus, Escherichia coli and Morganella morganii (MICs $=5 \mathrm{mg} / \mathrm{mL}$ ). The obtained results evidence that the fig peel is superior to the corresponding pulp as it relates to nutritional and phenolic profiles as well as bioactivities, endorsing the urgency in valorising and exploiting this usually discarded industrial by-product.
\end{abstract}

\section{Introduction}

Figs are the infrutecences of trees belonging to the Ficus genus, family Moraceae, which comprises $>800$ distinct species that adapt well to warm and dry climates (Meziant, Boutiche, Bey, Saci, \& Louaileche, 2018; Arvaniti, Samaras, Gatidou, Thomaidis, \& Stasinakis, 2019). The tasty and nutritive fruit of the species Ficus carica L., also known as common fig, have been cultivated and appreciated by humankind since ancient times (Barolo, Mostacero, \& López, 2014; Rodríguez-Solana, Galego, Pérez-Santín, \& Romano, 2018). The fig fruit is seasonal, harvested twice a year; its skin color may range from dark purple to green, depending on the variety (Kamiloglu \& Capanoglu, 2015). Figs are substantial sources of trace minerals (above all calcium, but also iron and potassium) and vitamins (mostly thiamin and riboflavin); in addition, present a high number of essential amino acids, and great contents of fibers and antioxidant phytochemicals (especially phenolic acids, flavonoids and carotenoids) (Arvaniti et al., 2019; Viuda-Martos, Barber, Perez-Alvarez, \& Fernandez-Lopez, 2015).

For millennia $F$. carica has been applied in folk medicine to treat a series of illnesses related to digestive, endocrine, reproductive, and respiratory systems; gastrointestinal tract; urinary system infection, and skin diseases (Badgujar, Patel, Bandivdekar, \& Mahajan, 2014; Shi et al., 2018). Sundry bioactivities, including antihyperlipidemic, antioxidant, antibacterial, antiprofilerative, anti-diabetic, antiobesogenic and hepatoprotective (Debib et al., 2016) effects, have been assessed and confirmed on fig fruit extracts by several in vivo and in vitro studies (Debib et al., 2016; Mopuri, Ganjayi, Meriga, Koorbanally, \& Islam, 2018).

Nowadays, most of the world's fig production takes place in the Middle East and Mediterranean region. In 2017, > 1.15 million tons were yielded worldwide, with Turkey accounting for almost $27 \%$ of the global supply, followed by Egypt, Algeria, Morocco, Iran, Spain and

\footnotetext{
* Corresponding authors.

E-mail addresses: lillian@ipb.pt (L. Barros), iferreira@ipb.pt (I.C.F.R. Ferreira).
} 
Greece (FAO - Food and Agriculture Organization, 2017). Although the Portuguese fig production represents only a small part of the European contribution, yet it is an important crop for Portugal (FAO - Food and Agriculture Organization, 2017). Culturally valued by the Portuguese people, figs are consumed in natura or used as raw material by wine, liquor, jelly, and jam industries (Buenrostro-Figueroa et al., 2017). In the $F$. carica industrial processing, the pulp is used whereas the peel is discarded (Kamiloglu \& Capanoglu, 2015); which generates a significant volume of by-products consisting of inadequate fruits (the overripe ones) and peels (Buenrostro-Figueroa et al., 2017; ViudaMartos et al., 2015). Since these materials are proven to be abundant in nutrients and bioactive phytochemicals, concentrating the majority of the fig's phenolic compounds, their valorization and exploitation have been recently proposed by some authors (Viuda-Martos et al., 2015; Buenrostro-Figueroa et al., 2017; Backes et al., 2018; Meziant, et al. 2018).

In the past years, several groups have investigated the polyphenol constitution of the distinct parts of $F$. carica fruits (fresh and/or dried) from Israel (Solomon et al., 2006), Italy (Del Caro \& Piga, 2008), Portugal (Oliveira et al., 2009), Turkey and Greece (Kamiloglu \& Capanoglu, 2015; Russo, Caporaso, Paduano, \& Sacchi, 2014), Albania (Hoxha \& Kongoli, 2016), Pakistan (Ajmal et al., 2016), Tunisia (Ammar, del Mar Contreras, Belguith-Hadrich, Segura-Carretero, \& Bouaziz, 2015; Harzallah, Bhouri, Amri, Soltana, \& Hammami, 2016), Iran (Maghsoudlou, Esmaeilzadeh Kenari, \& Raftani Amiri, 2017), Spain (Pereira et al., 2017; Vallejo, Marín, \& Tomás-Barberán, 2012; Wojdyło, Nowicka, Carbonell-Barrachina, \& Hernández, 2016), Algeria (Mahmoudi et al., 2018; Meziant et al. 2018), India and South Africa (Mopuri et al., 2018). Some authors have studied the volatile profile of many Portuguese fig cultivars (Oliveira et al., 2010; Rodríguez-Solana et al., 2018), whereas a recent work of our group demonstrated the feasibility of recovering bioactive anthocyanin pigments from the peel of a Portuguese purple fig variety via emerging technologies (Backes et al., 2018). Nevertheless, to our best knowledge, there are still no reports on the advanced phenolic characterization of Portuguese fig fruits nor on differences in single phenolic compounds in their peel and pulp parts.

This study aims to give an unprecedented contribution on the chemical composition and bioactivities of a very common and appreciated Portuguese fig variety ("Pingo de Mel") with the view of expanding the knowledge on its potentialities. For this purpose, its peel and pulp were comparatively characterized in terms of macronutrients, free sugars, organic acids, tocopherols and fatty acids. Furthermore, the phenolic profiles of their hydroethanolic extracts were determined, as well as their antioxidant and antibacterial potentials.

\section{Materials and methods}

\subsection{Standards and reagents}

Acetonitrile $99.9 \%$ was of HPLC grade from Fisher Scientific (Lisbon, Portugal). Trolox (6-hydroxy-2,5,7,8-tetramethylchroman-2carboxylic acid), sugar, organic acid and phenolic compound standards were from Sigma (St. Louis, MO, USA). Racemic tocol $\left(50 \mathrm{mg} \mathrm{mL}^{-1}\right)$ and tocopherols, were purchased from Matreya (PA, USA). 2,2Diphenyl-1-picrylhydrazyl (DPPH) was obtained from Alfa Aesar (Ward Hill, MA, USA). Dimethylsulfoxide (DMSO) (Merck KGaA, Germany) was used as a solvent in antimicrobial assays. Ethanol and all other chemicals were of analytical grade and purchased from common sources. Water was treated in a Milli-Q water purification system (TGI Pure Water Systems, Greenville, SC, USA).

\subsection{Samples}

The infructescences of $F$. carica variety "Pingo de Mel" were collected from a domestic production at the municipality of Bragança,
Trás-os-Montes, Northeast of Portugal, in summer 2017. Two kilos of ripped fruits were selected, washed in running potable water, sanitized with sodium hypochlorite by immersion, and manually de-pulped. The lyophilized samples were and kept at $-20^{\circ} \mathrm{C}$ until analysis. Then, peel and pulp materials were separately frozen at $-80^{\circ} \mathrm{C}$ and thereafter freeze-dried (Zirbus Technonoly VaCo 10-II, Bad Grund, Germany) at $-85^{\circ} \mathrm{C}$ and 0.2 mbar.

\subsection{Nutritional and chemical composition}

The nutritional composition of the peel and pulp parts was estimated employing standard procedures (AOAC, 2016). The crude protein $(\mathrm{N} \times 6.25)$ was determined using the macro-Kjeldahl method and the ash content via incineration at $550 \pm 15^{\circ} \mathrm{C}$. The crude fat was estimated by extracting a known weight of lyophilized sample with petroleum ether in a Soxhlet apparatus, the ash content via incineration at $550 \pm 15{ }^{\circ} \mathrm{C}$, and the total carbohydrate amount was estimated by difference. Finally, the total energy value was calculated through the equation: Energy $(\mathrm{kcal})=4 \times\left(\mathrm{g}_{\text {proteins }}+\mathrm{g}_{\text {carbohydrates }}\right)+9 \times\left(\mathrm{g}_{\text {lipids }}\right)$.

Free sugars were determined via high performance liquid chromatography coupled to a refraction index detector (HPLC-RI; Knauer, Smartline system 1000, Berlin, Germany), employing melezitose as the internal standard, according to the method of Barros, Pereira, and Ferreira (2013). Results were given in $\mathrm{g}$ per $100 \mathrm{~g}$ of fresh weight (fw).

Organic acids were assessed via liquid chromatography coupled to photodiode array detector (Shimadzu 20A series UFLC, Shimadzu Cooperation), as described by Barros, Pereira, and Ferreira (2013). Detection was accomplished using 215 and $245 \mathrm{~nm}$ as preferred wavelengths. Quantification was done by comparison of the area of the peaks recorded at $215 \mathrm{~nm}$ with calibration curves obtained from commercial standards of each organic acid. The results were expressed in mg per $100 \mathrm{~g}$ of fresh weight (fw).

Tocopherols were analyzed in a Knauer Smartline system 1000 (HPLC, Berlin, Germany) coupled to a fluorescence detector (FP-2020; Jasco, Easton, USA) using the internal standard methodology, as described by Pereira, Barros, Carvalho, and Ferreira (2013). Identification was performed comparing the tocopherols retention times with authentic standard compounds and quantification was achieved by comparison with dose-response curves constructed from authentic standards, using the IS (tocol) method. The results were given in mg per $100 \mathrm{~g}$ of fresh weight.

The fatty acids (FAs) were assessed by gas chromatography coupled with a flame ionization detector (GC-FID/capillary column, DANI model GC 1000, Contone, Switzerland), a split/splitless injector and a Macherey-Nagel column; their identification was achieved by comparing the relative retention times of FAME peaks from samples with commercial standards (Barros, Pereira, et al., 2013). Results were given in relative percentage of each FA.

\subsection{Preparation of the hydroethanolic extracts}

The lyophilized peel and pulp samples $(\sim 1 \mathrm{~g})$ were extracted with an ethanol/water extractor solution $(80: 20, \mathrm{v} / \mathrm{v} ; 30 \mathrm{~mL})$, at $25^{\circ} \mathrm{C}$ and $150 \mathrm{rpm}$ during $1 \mathrm{~h}$, followed by filtration (Whatman No. 4). Subsequently, the process was repeated with the residue, and the combined extracts were then concentrated under reduced pressure at $40{ }^{\circ} \mathrm{C}$ (rotary evaporator Büchi R-210, Flawil, Switzerland). Finally, the aqueous phase was lyophilized and the dried extracts were stored under $-20^{\circ} \mathrm{C}$ until analysis.

\subsection{Phenolic compounds characterization}

The phenolic profiles were determined via liquid chromatography with photo-diode array detection coupled to electrospray ionization tandem mass spectrometry (LC-DAD-ESI/MSn) (Dionex Ultimate 3000 UPLC, Thermo Scientific, San Jose, CA, USA), according to the protocol 
established by the authors (Bessada, Barreira, Barros, Ferreira, \& Oliveira, 2016). Prior to the chromatographic analysis, the lyophilized extracts were dissolved in an ethanol:water $(80: 20, \mathrm{v} / \mathrm{v})$ mixture. The detection was accomplished with a photodiode array detector (DAD) with 280, 330 and $370 \mathrm{~nm}$ as preferred wavelengths, and in a Linear Ion Trap LTQ XL mass spectrometer (Thermo Finnigan, San Jose, CA, USA) equipped with an ESI source operating in negative mode. Identification was achieved using commercial standard compounds (when possible) or by comparison with literature data. For each standard (Extrasynthèse, Genay, France), calibration curves were built using the UV signal. Quantification was done with the most fitting compound, and results were given in $\mathrm{mg}$ per $\mathrm{g}$ of extract.

\subsection{Antioxidant activity evaluation}

The lyophilized extracts were re-dissolved in ethanol:water (80:20, $\mathrm{v} / \mathrm{v}$ ) to achieve stock solutions, which were further diluted to provide a range of concentrations. Samples' antioxidant potentials were evaluated by three classical in vitro chemical-based methods, namely the DPPH radical-scavenging, the reducing power, and the inhibition of $\beta$-carotene bleaching assays; and by two cellular antioxidant activity (CAA) tests, specifically the inhibition of the production of thiobarbituric acid reactive substances assay (TBARS), and the oxidative haemolysis inhibition assay (OxHLIA). The first four methods were executed as related by Corrêa et al. (2015), with results expressed as IC $_{50}$ values (mg/ $\mathrm{mL}$ ), i.e., extract concentration providing $50 \%$ of antioxidant activity.

The OxHLIA method was performed according to the protocol minutely described by Lockowandt et al. (2019). The erythrocytes employed in this assay were prepared according to Evans et al. (2013). Briefly, in a 48 -well microplate, $200 \mu \mathrm{L}$ of erythrocyte solution was mixed with $400 \mu \mathrm{L}$ of either PBS solution (control); antioxidant samples were homogenized in PBS, or water (to induce full haemolysis). After an incubation period $\left(37^{\circ} \mathrm{C}, 10 \mathrm{~min}\right.$, with shaking), $200 \mu \mathrm{L}$ of $2,2^{\prime}$-azobis (2-methylpropionamidine) dihydrochloride $(160 \mathrm{mM}$ in PBS) was added and the plate was incubated once more, under identical conditions. Then, optical density was assessed at $690 \mathrm{~nm}$ every $10 \mathrm{~min}$, with results expressed as delayed time of haemolysis $(\Delta t)$ (Takebayashi, Iwahashi, Ishimi, \& Tai, 2012). The obtained $\Delta \mathrm{t}$ values were correlated to the distinct sample concentrations, and from this correlation the inhibitory concentration capable of supplying $60 \mathrm{~min}$ and $120 \mathrm{~min}$ haemolysis delays $(\Delta \mathrm{ts})$ were determined. Results were given in extract concentration needed to protect $80 \%$ of the erythrocyte population from the haemolytic action caused by the oxidizing agent ( $\mathrm{IC}_{80}, \mathrm{mg}$ / $\mathrm{mL})$.

\subsection{Antibacterial activity evaluation}

The minimal inhibitory and bactericidal concentrations (MIC and $\mathrm{MBC}$ ) for all the bacterial strains were determined using a protocol established by the authors and described by Pires et al. (2018). Five Gram-negative bacteria and four Gram-positive bacteria were employed in this assay, in which the antibiotics ampicillin and imipenem were used as positive controls for the Gram-negatives, whereas ampicillin and vancomycin for the Gram-positives.

\subsection{Statistical analysis}

All obtained data were expressed as mean values and standard deviations (SD), as a result of the three repetitions of the samples and concentrations that were employed in all analysis. To determine significant differences, among two different samples (peel and pulp) with $\alpha=0.05$, the Student's $t$-test was applied. Analyses were performed with the IBM SPSS Statistics for Windows, version 23.0. (IBM Corp., Armonk, New York, USA).
Table 1

Macronutrients ( $\mathrm{g} / 100 \mathrm{~g} \mathrm{fw}$ ) and energy value (kcal/100 $\mathrm{g}$ fw) of the Ficus carica pulp and peel parts.

\begin{tabular}{llll}
\hline & Peel & Pulp & $t$-Student test p-value \\
\hline Moisture & $67 \pm 3$ & $72 \pm 1$ & 0.132 \\
Ash & $1.01 \pm 0.05$ & $0.79 \pm 0.01$ & $<0.001$ \\
Protein & $2.2 \pm 0.1$ & $1.99 \pm 0.03$ & 0.021 \\
Fat & $1.64 \pm 0.03$ & $1.24 \pm 0.03$ & $<0.001$ \\
Carbohydrates & $27.8 \pm 0.1$ & $23.74 \pm 0.01$ & $<0.001$ \\
Energy & $134.7 \pm 0.2$ & $114.1 \pm 0.1$ & $<0.001$ \\
\hline
\end{tabular}

A Student's $t$-test was used to determine the significant difference between two different samples, with $\alpha=0.05: \mathrm{p}<.001$ means a significant difference between the samples.

Table 2

Composition in free sugars $(\mathrm{g} / 100 \mathrm{~g} \mathrm{fw})$, organic acids $(\mathrm{mg} / 100 \mathrm{~g} \mathrm{fw})$, and tocopherols (mg/100 $\mathrm{g} \mathrm{fw}$ ) of the Ficus carica pulp and peel parts.

\begin{tabular}{llll} 
& Peel & Pulp & $\begin{array}{l}t \text {-Student test p- } \\
\text { value }\end{array}$ \\
\hline Fructose & $17.4 \pm 0.1$ & $13.16 \pm 0.09$ & $<0.001$ \\
Glucose & $21.0 \pm 0.2$ & $15.7 \pm 0.1$ & $<0.001$ \\
Sucrose & $4.83 \pm 0.02$ & $2.975 \pm 0.002$ & $<0.001$ \\
Trehalose & $0.21 \pm 0.01$ & $0.161 \pm 0.001$ & 0.001 \\
Total sugars & $43.4 \pm 0.4$ & $32.0 \pm 0.2$ & $<0.001$ \\
Oxalic acid & $143 \pm 1$ & $228 \pm 3$ & $<0.001$ \\
Quinic acid & $128 \pm 5$ & $72 \pm 5$ & $<0.001$ \\
Malic acid & $165 \pm 4$ & $91 \pm 2$ & $<0.001$ \\
Citric acid & $827 \pm 37$ & $259 \pm 12$ & $<0.001$ \\
Succinic acid & $317 \pm 13$ & $484 \pm 4$ & $<0.001$ \\
Total organic acids & $1580 \pm 58$ & $1134 \pm 6$ & $<0.001$ \\
$\alpha$-Tocopherol & $2.75 \pm 0.06$ & $0.93 \pm 0.03$ & $<0.001$ \\
$\beta$-Tocopherol & $0.0157 \pm 0.0004$ & $0.0073 \pm 0.0001$ & $<0.001$ \\
$\gamma$-Tocopherol & $1.30 \pm 0.02$ & $2.68 \pm 0.09$ & $<0.001$ \\
$\delta$-Tocopherol & $0.068 \pm 0.002$ & $0.109 \pm 0.002$ & $<0.001$ \\
Total tocopherols & $4.14 \pm 0.04$ & $3.7 \pm 0.1$ & 0.004 \\
\hline
\end{tabular}

A Student's $t$-test was used to determine the significant difference between two different samples, with $\alpha=0.05: \mathrm{p}<.001$ means a significant difference between the samples.

\section{Results and discussion}

\subsection{Nutritional and chemical composition}

The composition of macronutrients, free sugars, organic acids, tocopherols, and fatty acids of our $F$. carica peel and pulp samples were determined, and the obtained results are displayed in Tables 1-3.

As shown in Table 1, our peel sample presented significantly higher contents of ash, fat and carbohydrates, and consequently higher energy value, than the corresponding pulp. There were no significant differences regarding their moisture and protein contents. Ajmal et al. (2016), in their characterization study of the distinct parts of a black variety of common fig, verified higher moisture contents (84.24 and $74.56 \mathrm{~g} / 100 \mathrm{~g}$, respectively for pulp and peel). They also verified a higher ash content $(1.78 \mathrm{~g} / 100 \mathrm{~g})$ for their peel sample; however, their pulp's ash content was very similar to ours. Regarding their protein contents, the value reported for the peel (almost $3 \mathrm{~g} / 100 \mathrm{~g}$ ) was superior to ours, whereas the verified pulp's import $(1 \mathrm{~g} / 100 \mathrm{~g})$ was half of our value. Furthermore, the authors reported much lower fat amounts for their peel and pulp samples, 0.38 and $0.2 \mathrm{~g} / 100 \mathrm{~g}$, respectively. Mamoudi et al. (2018) recently estimated the proximal components of fresh figs from nine cultivars grown in Algeria. They found a mean carbohydrate amount of 4.84 for the peel, which is a much lower than ours $(27.8 \pm 0.1 \mathrm{~g} / 100 \mathrm{~g} \mathrm{fw})$, whereas an average content of $19.48 \mathrm{~g}$ / $100 \mathrm{~g}$ fw for the pulp. The authors also verified that the mean protein concentration of the fig peel $(1.06 \mathrm{~g} / 100 \mathrm{~g} \mathrm{fw})$ were just slightly higher than that of the pulp $(1.03 \mathrm{~g} / 100 \mathrm{~g} \mathrm{fw})$.

Four free sugars were detected in our F. carica samples (Table 2). 
Table 3

Fatty acid compositions of the Ficus carica peel and pulp, in relative percentage of each fatty acid.

\begin{tabular}{llll}
\hline & Peel & Pulp & $t$-Student test p-value \\
\hline C6:0 & $0.583 \pm 0.002$ & nd & - \\
C8:0 & $0.38 \pm 0.02$ & $0.093 \pm 0.004$ & $<0.001$ \\
C10:0 & $0.970 \pm 0.002$ & $0.179 \pm 0.001$ & $<0.001$ \\
C11:0 & nd & $0.233 \pm 0.009$ & - \\
C12:0 & $0.96 \pm 0.07$ & $0.085 \pm 0.004$ & $<0.001$ \\
C14:0 & $3.06 \pm 0.06$ & $0.50 \pm 0.05$ & $<0.001$ \\
C14:1 & $0.099 \pm 0.003$ & nd & - \\
C15:0 & $0.53 \pm 0.05$ & $0.30 \pm 0.03$ & $<0.001$ \\
C16:0 & $23.9 \pm 0.1$ & $11.2 \pm 0.3$ & $<0.001$ \\
C16:1 & $0.30 \pm 0.02$ & $0.121 \pm 0.001$ & $<0.001$ \\
C17:0 & $0.53 \pm 0.03$ & $0.214 \pm 0.005$ & $<0.001$ \\
C18:0 & $6.0 \pm 0.1$ & $3.91 \pm 0.04$ & $<0.001$ \\
C18:1n9 & $12.2 \pm 0.1$ & $8.8 \pm 0.1$ & $<0.001$ \\
C18:2n6 & $12.6 \pm 0.2$ & $19.9 \pm 0.2$ & $<0.001$ \\
C18:3n3 & $28.0 \pm 0.7$ & $51.8 \pm 0.4$ & $<0.001$ \\
C20:0 & $4.39 \pm 0.09$ & $0.84 \pm 0.03$ & $<0.001$ \\
C20:1 & $0.129 \pm 0.001$ & $0.14 \pm 0.01$ & $<0.001$ \\
C20:2 & nd & $0.153 \pm 0.006$ & - \\
C21:0 & $0.15 \pm 0.01$ & $0.084 \pm 0.006$ & 0.077 \\
C22:0 & $2.60 \pm 0.05$ & $0.82 \pm 0.07$ & $<0.001$ \\
C22:2 & $0.267 \pm 0.002$ & nd & - \\
C23:0 & $0.263 \pm 0.001$ & $0.139 \pm 0.008$ & $<0.001$ \\
C24:0 & $2.184 \pm 0.01$ & $0.386 \pm 0.004$ & $<0.001$ \\
Total SFA & $46.5 \pm 0.6$ & $19.0 \pm 0.5$ & $<0.001$ \\
Total MUFA & $12.7 \pm 0.2$ & $9.1 \pm 0.1$ & $<0.001$ \\
Total PUFA & $40.8 \pm 0.5$ & $71.9 \pm 0.6$ & $<0.001$ \\
& & & \\
\hline
\end{tabular}

Caproic acid (C6:0); Caprylic acid (C8:0); Capric acid (C10:0); Undecanoic acid (C11:0); Lauric acid (C12:0); Myristic acid (C14:0); Myristoleic acid (C14:1); Pentadecanoic acid (C15:0); Palmitic acid (C16:0); Palmitoleic acid (C16:1); Heptadecanoic acid (C17:0); Stearic acid (C18:0); Oleic acid (C18:1n9); Linoleic acid (C18:2n6); $\alpha$-Linolenic acid (C18:3n3); Arachidic acid (C20:0); Eicosenoic acid (C20:1); cis-11,14-Eicosadienoic acid (C20:2); Heneicosanoic acid (C21:0); Behenic acid (C22:0); cis-13,16-Docosadienoic acid (C22:2); Tricosanoic acid (C23:0); Lignoceric acid (C24:0); Saturated fatty acids (SFA); Monounsaturated fatty acids (MUFA); Polyunsaturated fatty acids (PUFA). A Student's $t$-test was performed to determine the significant between two different samples, with $\alpha=0.05: p<.001$ means a significant difference between the samples. nd not detected.

Glucose was the principal sugar for both of them $(21.0 \pm 0.2$ and $15.7 \pm 0.2 \mathrm{~g} / 100 \mathrm{~g} \mathrm{fw}$, for peel and pulp, respectively), followed by fructose and sucrose, in addition to threalose in very low amounts. Wojdyło et al. (2016), when investigating the composition of 10 fig varieties, also verified that fructose and glucose were the major sugars in all analyzed fruits, whilst sucrose was found in lower amounts. They reported total sugar contents ranging from 44.0 to $74.3 \mathrm{~g} / 100 \mathrm{~g} \mathrm{dm}$. Our peel sample presented higher amounts of all detected sugars; therefore, its total free sugars content $(43.4 \pm 0.4 \mathrm{~g} / 100 \mathrm{~g} \mathrm{fw})$ was 1.35 -fold higher than the pulp's content.

Five organic acids were identified and quantified in our $F$. carica samples, namely oxalic, quinic, malic, citric, and succinic acids (Table 2). The citric acid was the most abundant component in the peel $(827 \pm 37 \mathrm{mg} / 100 \mathrm{~g})$ whereas succinic acid was the most abundant in the pulp ( $484 \pm 4 \mathrm{mg} / 100 \mathrm{~g}$ ); these compounds accounted for $52 \%$ and $43 \%$ of samples total organic acids contents, respectively. The total organic acids content of our peel sample was almost 1.4-fold higher than the pulp's content. Pande and Akoh (2010) studied the composition of the 'Brown Turkey' variety whole fig fruit and peels, and reported the detection of malic, citric, ascorbic, succinic, and oxalic acids for both samples, which corroborates our verified profiles. The major organic acids in their fig peel sample were malic, citric and ascorbic acids, found in concentration values of $0.45,0.18$ and $0.10 \mathrm{mg} / \mathrm{g} \mathrm{fw}$, respectively.

Tocopherols were detected in all their four forms $(\alpha, \beta, \delta$ and $\gamma)$ in our samples (Table 2). $\alpha$-Tocopherol was the major component in the peel $(2.75 \pm 0.06 \mathrm{mg} / 100 \mathrm{~g} \mathrm{fw})$, whereas the $\gamma$-tocopherol was the most abundant in the pulp $(2.68 \pm 0.09 \mathrm{mg} / 100 \mathrm{~g} \mathrm{fw})$. $\beta$-Tocopherol was found only in very low amounts in both samples. Pande and Akoh (2010) reported inferior concentrations of $\alpha$-tocopherol $(0.2 \mathrm{mg} / 100 \mathrm{~g}$ $\mathrm{fw}), \gamma$-tocopherol $(0.3 \mathrm{mg} / 100 \mathrm{~g} \mathrm{fw})$, and $\beta$-tocopherol (trace concentrations) when analyzing a $F$. carica whole-fruit sample; furthermore, they did not detect $\delta$-tocopherol.

Twenty-three different fatty acids (FAs) were found in our $F$. carica extracts, with amounts given in relative percentage (Table 3). The $\alpha$ linolenic acid (C18:3n3) was the most abundant component of both samples, accounting for $>50 \%$ of the pulp's total FA content and of almost $30 \%$ of the peel's content, followed by linoleic (C18:2n6), palmitic (C16:0), and oleic (C18:1n9) acids. Marrelli et al. (2012) verified similar FA profile when analyzing a $n$-hexane fraction of a hydroethanolic extract (70\% ethanol) from fresh figs cultivated in Italy. The major FAs detected in their n-hexane fraction were linolenic (up to $35 \%$ ), oleic and palmitic acids. Badgujar et al. (2014) also reported that linolenic acid was the main FA component (53\%) of dried fig fruits, followed by linoleic acid (21\%), palmitic acid (14\%), and oleic acid (10\%). However, Pande and Akoh (2010) found that linoleic acid (28\%) was the predominant FA in the fig whole-fruit, followed by the palmitic, oleic and linonelic acids.

As expected, there were significant differences in the FA compositions of our peel and pulp extracts. The peel extract presented 21 FAs, as the undecanoic (C11:0) and the cis-11,14-eicosadienoic (C20:2) acids were not detected in this sample, although present in the pulp in very small amounts $(<1 \%)$. On the other hand, 20 FAs were detected in the pulp; caproic (C6:0), myristoleic (C14:1), and cis-13,16-docosadienoic (C22:2) acids were absent from this sample. Furthermore, the saturated fatty acids (SFA) percentage found in the peel were $>2$-fold the content verified in the pulp, which on its turn had considerably superior polyunsaturated fatty acids (PUFA) tenor ( $>$ 1.76-fold higher).

\subsection{Phenolic compounds profiles}

The phenolic compositions of the hydroethanolic peel and pulp extracts of $F$. carica are presented in Table 4. Eighteen phenolic compounds were detected (Fig. 1), among which eight flavonoid derivatives, eight phenolic acids and derivatives, and two compounds which definite identification could not be assigned. To our best knowledge, there are no previous reports containing the in-depth phenolic characterization of a green fig variety from Portugal.

Regarding the phenolic acids found in fig samples, caffeic and vanillic acid derivatives were the predominant compounds. Peak 1 and 2, both presented the same pseudomolecular ion $[\mathrm{M}-\mathrm{H}]^{-}$at $m / z 341$, with a characteristic $\mathrm{MS}^{2}$ fragment at $m / z 179$ [caffeic acid - H] ${ }^{-}$(loss of $162 \mathrm{u}$, corresponding to an hexosyl moiety), being both tentatively identified as caffeic acid hexoside. Peak 3 was positively identified as 5$O$-caffeoylquinic acid in comparison with the commercial standard. Peak 16 was assigned as cinnamoyl-amino acid conjugate, the tentative identification of this compound was possible comparing the chromatographic characteristics with the ones reported by Alonso-Salces, Guillou, and Berrueta (2009) for conjugated cinnamoyl-amino acids identified in green coffee beans. Peak 16 showed a UV spectra $\lambda_{\max }$ around $325 \mathrm{~nm}$ characteristic of hydroxycinnamic acids, and presented a pseudomolecular ion $[\mathrm{M}-\mathrm{H}]^{-}$at $m / z 527$ followed by a major $\mathrm{MS}^{2}$ fragment at $m / z 365$ (attributed to the loss of a hexose moiety, $162 \mathrm{u}$ ) and a fragment at $m / z 203$ coherent with the amino acid tryptophan, being tentatively identified as caffeoyl $N$-tryptophan hexoside. Peaks 5 , 7 , and 13 were assigned as vanillic acid derivatives, taking into account its UV-Vis spectra and MS fragmentation pattern. Peak $5\left([\mathrm{M}-\mathrm{H}]^{-}\right.$at $m /$ $z$ 313) and $7\left([\mathrm{M}-\mathrm{H}]^{-}\right.$at $\left.m / z 459\right)$ showed a UV spectra $\lambda_{\max }$ around $253,292 \mathrm{~nm}$ and $\mathrm{MS}^{2}$ fragment at $\mathrm{m} / z 167$ [vanillic acid - H] ${ }^{-}$(corresponding to one and two deoxyhexosyl moieties, respectively), being tentatively assigned as vanillic acid deoxyhexoside and vanillic acid dideoxyhexoside, respectively. Similarly, peak $13\left([\mathrm{M}-\mathrm{H}]^{-}\right.$at $\left.\mathrm{m} / \mathrm{z} 545\right)$ 


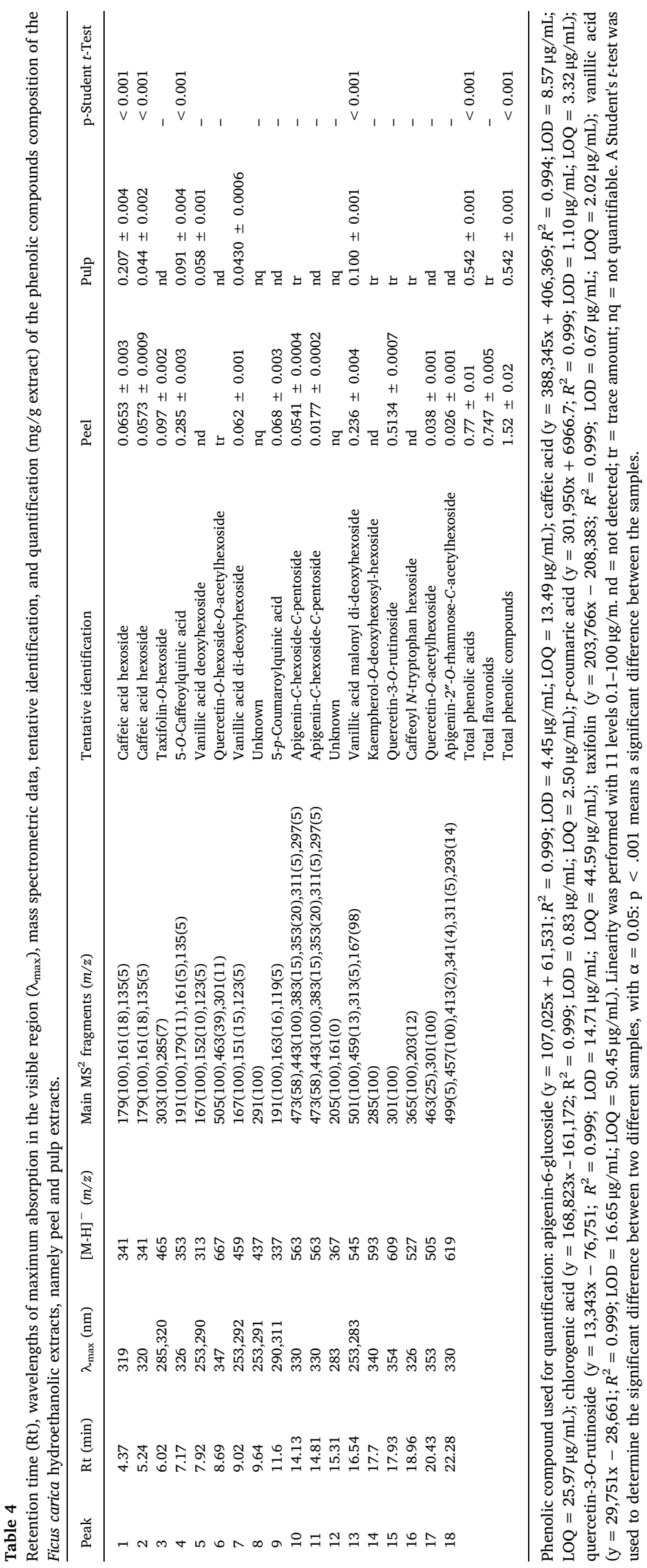



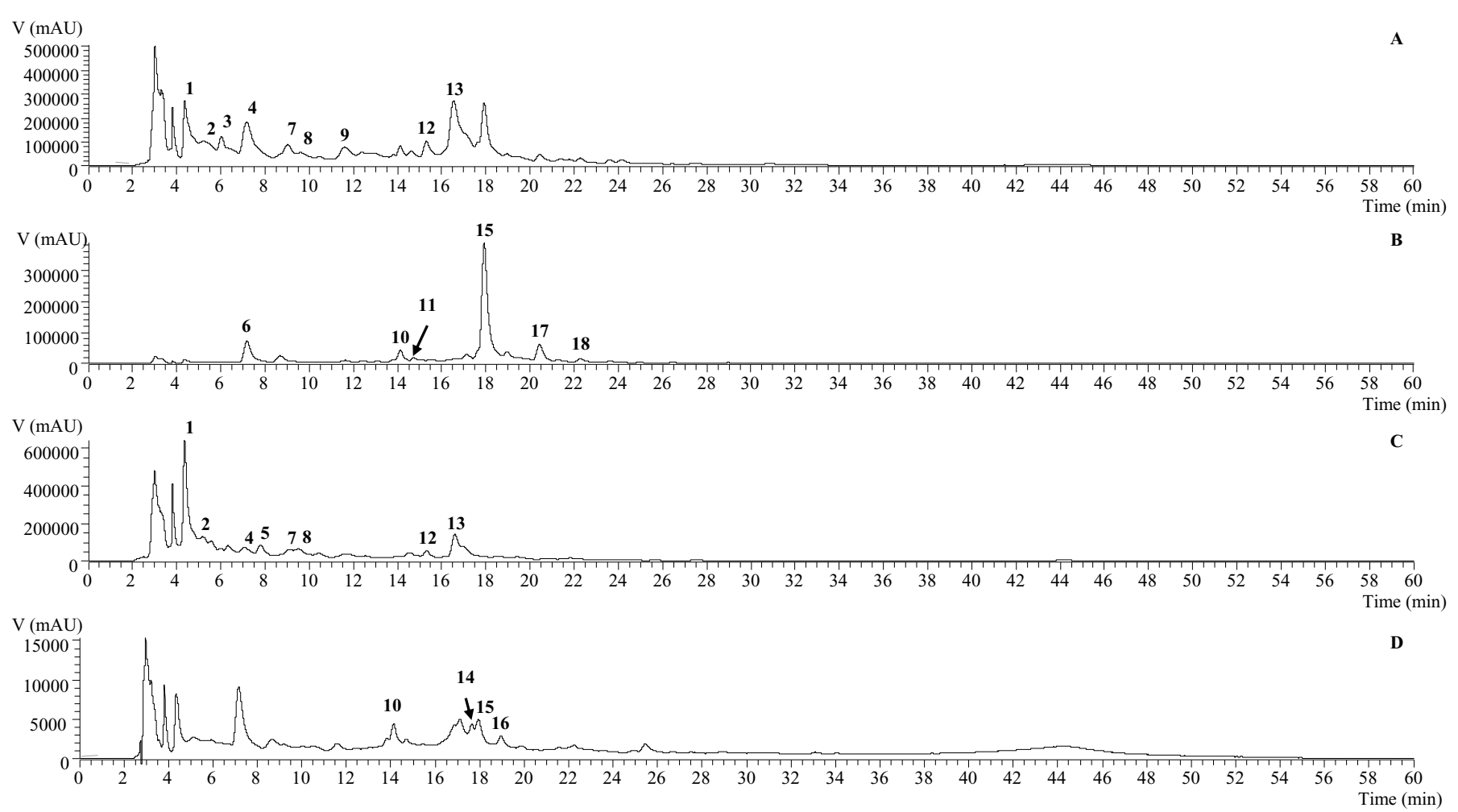

Fig. 1. Chromatographic profile of the peel (A and B) and pulp (C and D) parts of the fig recorded at 280 (A and C, respectively) and $370 \mathrm{~nm}$ (B and D, respectively).

presented $\mathrm{MS}^{2}$ fragments at $\mathrm{m} / z 501(44 \mathrm{u}), 459$ (42 u), 313 (146 u), and $167(146 \mathrm{u})$, corresponding to the loss of a malonyl and two deoxyhexosyl moieties, being tentatively assigned as vanillic acid malonyl di-deoxyhexoside. Finally, peak $9\left([\mathrm{M}-\mathrm{H}]^{-}\right.$at $m / z$ 337) was assigned to 5-p-coumaroylquinic acid, using the hierarchical key system previously reported by Clifford, Johnston, Knight, and Kuhnert (2003).

Among the eight flavonoids glycoside derivatives found in fig samples, quercetin and $C$-glycosylated apigenin derivatives were the most representatives, followed by kaempherol and taxifolin derivatives. Peak $15\left([\mathrm{M}-\mathrm{H}]^{-}\right.$at $\left.m / z 609\right)$ was assigned as quercetin-3-O-rutinoside (rutin), by comparing its retention time and $\lambda_{\max }$ with the available commercial standard. Peak $6\left([\mathrm{M}-\mathrm{H}]^{-}\right.$at $\mathrm{m} / \mathrm{z}$ 667) revealed three $\mathrm{MS}^{2}$ fragments at $m / z 505,463$, and 301 (quercetin aglycone), which corresponded to the losses of two hexosyl and acetyl moieties, being tentatively assigned as quercetin- $O$-hexoside- $O$-acetylhexoside. Similarly, peak $17\left([\mathrm{M}-\mathrm{H}]^{-}\right.$at $m / z$ 505) was assigned as quercetin- $O$-acetylhexoside. Peak $14\left([\mathrm{M}-\mathrm{H}]^{-}\right.$at $m / z$ 593) corresponded to a kaempherol derivative, due to its UV-vis characteristic with a $\lambda_{\max }$ at 263 and $340-348 \mathrm{~nm}$. This peak revealed a unique $\mathrm{MS}^{2}$ fragment at $\mathrm{m} / \mathrm{z}$ 285 , corresponding to the loss of $308 \mathrm{u}$ (deoxyhexosyl-hexosyl moiety), thus presenting a lower retention time then kaempherol-3-O-rutinoside (commercial standard with a $\mathrm{Rt}=21.3 \mathrm{~min}$ ), being tentatively identified as kaempherol-O-deoxyhexosyl-hexoside. Peak $3\left([\mathrm{M}-\mathrm{H}]^{-}\right.$at $m / z$ 465) was assigned to a dihydroquercetin derivative ([taxifolin- $\mathrm{H}]^{-}$), revealing a major $\mathrm{MS}^{2}$ fragment at $m / z 303$, resulting from the loss of a hexosyl moiety $(-162 \mathrm{u})$, thus being tentatively assigned as taxifolin$\mathrm{O}$-hexoside.

$C$-glycosylated flavonoids (apigenin derivatives), were also found in the fig samples. Peaks 10 and $11\left([\mathrm{M}-\mathrm{H}]\right.$ at $m / z$ 563) released $\mathrm{MS}^{2}$ fragments corresponding to losses of $90 \mathrm{u}(\mathrm{m} / z$ at 473$)$ and $120 \mathrm{u}(\mathrm{m} / \mathrm{z}$ at 443), and at $m / z 383$ and 353 (apigenin aglycone plus residues, apigenin $+113 \mathrm{u}$ and apigenin $+83 \mathrm{u}$, respectively), allowing their tentative identification as apigenin- $C$-hexoside- $C$-pentoside (Ferreres, Silva, Andrade, Seabra, \& Ferreira, 2003). The last apigenin derivative (peak 18) was assigned as an $O$-glycosyl- $C$-glycosyl flavone according to the fragmentation patterns and abundances previously described (Ferreres et al., 2011; Ferreres, Gil-Izquierdo, Andrade, Valentao, \& Tomás-Barberán, 2007). Peak 18 ([M-H] at $m / z$ 619) presented a $\mathrm{MS}^{2}$ fragment ion at $m / z 499$ ([M-120]), characteristic of $C$-hexosyl flavones, and at $m / z 413$ ([M-146-18]), characteristic of an $O$-glycosylation on the hydroxyl group at position 2 of the $C$-glycosylation sugar (Ferreres et al., 2007). The other $\mathrm{MS}^{2}$ fragment ions at $m / z 341,311$, and 293 are also characteristics of this type of compounds, corresponding to the apigenin aglycone plus residues, being tentatively assigned as apigenin-2"-O-rhamnose- $C$-acetylhexoside.

Fifteen different phenolic components were detected in the peels, whereas 12 were detected in the pulp. Quercetin-3-O-rutinoside (rutin) was the major compound present in the peel extract, accounting for $33.8 \%$ of its phenolic content, followed by 5 -O-caffeoylquinic acid (5CQA, chlorogenic acid; $18.8 \%$ ), vanillic acid malonyl di-deoxyhexoside $(15.5 \%)$, and in minor amounts taxifolin, apigenin, quercetin, caffeic, and other vanillic acid derivatives (Table 4). Caffeic acid derivatives, such as caffeic acid hexosides, were the major components of the pulp extract, followed by vanillic acid derivatives (vanillic acid malonyl dideoxyhexoside, vanillic acid deoxyhexoside, and vanillic acid di-deoxyhexosideand), and 5-CQA. Rutin and apigenin derivatives were only found in trace amounts in this part of the sample.

Our results (Table 4) are in accordance with those present in literature data on the most important individual phenolic compounds detected in F. carica whole fruits (fresh and/or dried), as well as in their peel and pulp fractions. With respect to phenolic acids, gallic and syringic acids (hydroxylated derivatives of benzoic acid and chlorogenic acid), ferulic acid, caffeic and cinnamic acids (cinnamic acid derivatives) were the most often reported compounds. Regarding flavonoids, rutin (quercetin-3-O-rutinoside) and epicatechin were quantified in fresh fig samples in average concentrations of $0.68-0.38 \mathrm{mg} / \mathrm{g}$, and $0.77 \mathrm{mg} / \mathrm{g}$, respectively (Del Caro \& Piga, 2008; Oliveira et al., 2009; Vallejo et al., 2012; Kamiloglu \& Capanoglu, 2015; Pereira et al., 2017; Amessis-Ouchemoukh et al., 2017). Pereira et al. (2017) reported some phenolic compounds similar to ours when evaluating the composition 
of peel and pulp parts of nine fig varieties from Spain via HPLC-DAD/ ESI-MS. The authors detected phenolic acids like chlorogenic and ellagic acids, and flavonols such as rutin and quercetin-3-O-acetylglucoside. Regarding the amounts of phenolic acids, they reported chlorogenic acid contents of $0.6-2.1 \mathrm{mg} / 100 \mathrm{~g}$ fw for the peel samples and of $0.1-0.9 \mathrm{mg} / 100 \mathrm{~g}$ fw for the pulp samples, thus no comparison was achieved due to the different expressed units. Rutin ranged from 2.9 to 11.9 in the peel samples, and from 0.1 to $1.02 \mathrm{mg} / 100 \mathrm{~g} \mathrm{fw}$ in the pulp samples. Several authors have also verified a superior concentration of phenolic compounds in $F$. carica fruit peel in comparison with the corresponding pulp (Del Caro \& Piga, 2008; Oliveira et al., 2009; Vallejo et al., 2012; Kamiloglu \& Capanoglu, 2015; Pereira et al., 2017; Amessis-Ouchemoukh et al., 2017), which corroborates our findings.

The total phenolic content (TPC) found for our peel extract $(1.52 \pm 0.02 \mathrm{mg} / \mathrm{g})$ was almost 3-fold higher than the concentration verified for our pulp extract (Table 4). While our peel extract had a total flavonoid content (TFC) of almost $0.747 \pm 0.005 \mathrm{mg} / \mathrm{g}$, the corresponding pulp extract revealed trace amounts of this class of phenolic compounds; likewise, the peel's phenolic acids content $(0.77 \pm 0.01 \mathrm{mg} / \mathrm{g})$ was significantly higher than the value verified for the pulp $(0.542 \pm 0.001 \mathrm{mg} / \mathrm{g})$. Dozens of previous studies have evaluated the phenolic constitution of whole figs (fresh and/or dried, from very many varieties), and a great part of these papers comparatively assessed the fruits' peel and pulp fractions, using spectrophotometric and/or chromatographic approaches (Solomon et al., 2006; Del Caro \& Piga, 2008; Oliveira et al., 2009; Russo et al., 2014; Kamiloglu \& Capanoglu, 2015; Hoxha \& Kongoli, 2016; Ajmal et al., 2016; Ammar et al., 2015; Harzallah et al., 2016; Vallejo et al., 2012; Wojdyło et al., 2016; Maghsoudlou et al., 2017; Pereira et al., 2017; Mahmoudi et al., 2018; Meziant et al. 2018; Mopuri et al., 2018). In many cases, the TPCs were given in gallic acid equivalents (GAE)/g fw, whereas the TFCs were expressed as $m g(+)$-catechin equivalent $(\mathrm{CE}) / \mathrm{g}$ fw. Harzallah et al. (2016), for instance, studied the phenolic composition of the peel and pulp parts of a green fig variety (Bidhi) from Tunisia. The authors reported TPC values of $36 \mathrm{mg} \mathrm{GAE} / \mathrm{g}$ fw for the peel and of $39 \mathrm{mg} \mathrm{GAE} / \mathrm{g}$ fw for the pulp, and TFC values of 5 and $6 \mathrm{mg} \mathrm{CE} / \mathrm{g} \mathrm{fw}$ for the peel and pulp, respectively. Maghsoudlou et al. (2017) found considerably higher values of TPC and similar values of TFC when assessing Iranian green figs: $69 \mathrm{mg} \mathrm{GAE} / \mathrm{g}$ fw for the peel and $45.44 \mathrm{GAE} / \mathrm{g} \mathrm{fw}$ for the pulp, whereas $5.89 \mathrm{mgCE} / \mathrm{g} \mathrm{fw}$ and $5.47 \mathrm{mg} \mathrm{CE} / \mathrm{g}$ fw for peel and pulp, respectively.

Various monitoring and comparative works have evidenced that the phytochemical composition depends on the fig variety; however, it is also greatly influenced by other factors, e.g., coloration, the fraction analyzed (peel/pulp), maturity stage, edaphoclimatic conditions and eventual drying process (Kamiloglu \& Capanoglu, 2015; Bachir Bey, Richard, Meziant, Fauconnier, \& Louaileche, 2017; Harzallah et al., 2016; Pereira et al., 2017; Arvaniti et al., 2019).

\subsection{Evaluation of bioactive properties}

The antioxidant and antibacterial activities of the $F$. carica hydroethanolic extracts were assessed and the obtained results are displayed in Tables 5 and 6.

\subsubsection{Antioxidant activity}

Except for the study of Viuda-Martos et al. (2015), in which they analyzed figs by-products by the inhibition of the production of thiobarbituric acid reactive substances (TBARS) assay, we did not find reports on the use of cell-based approaches to assess the antioxidant capacity of $F$. carica extracts. Hence, to our best knowledge, the present work is the first report on the evaluation of $F$. carica extracts' antioxidant potential using such set of methods (DPPH, reducing power, $\beta$ carotene, TBARS, and OxHLIA assays).

Overall, our $F$. carica extracts presented promising antioxidant potentials in all tests; the peel extract displayed significantly lower $\mathrm{IC}_{50}$
Table 5

Antioxidant activity of the Ficus carica peel and pulp extracts evaluated by a set of different chemical and cell-based assays, expressed in $\mathrm{IC}_{50}(\mathrm{mg} / \mathrm{mL})$ and $\mathrm{IC}_{80}$ (mg/mL; for OxHLIA assay) values.

\begin{tabular}{llll}
\hline & Peel & Pulp & $\begin{array}{l}t \text {-Student test } \mathrm{p} \text { - } \\
\text { value }\end{array}$ \\
\hline $\begin{array}{l}\text { DPPH scavenging activity } \\
\text { Reducing power }\end{array}$ & $0.46 \pm 0.01$ & $1.13 \pm 0.05$ & $<0.001$ \\
$\begin{array}{l}\text { B-carotene bleaching } \\
\quad \text { inhibition }\end{array}$ & $0.135 \pm 0.03$ & $4.34 \pm 0.04$ & $<0.001$ \\
$\begin{array}{l}\text { TBARS inhibition } \\
\text { OxHLIA, } \Delta \mathrm{t}=60 \text { min }\end{array}$ & $1.14 \pm 0.04$ & $0.048 \pm 0.001$ & $<0.001$ \\
OxHLIA, $\Delta \mathrm{t}=120$ min & $0.85 \pm 0.05$ & $1.24 \pm 0.04$ & $<0.001$ \\
& $2.67 \pm 0.05$ & $3.36 \pm 0.06$ & 0.003 \\
& & & $<0.001$
\end{tabular}

Trolox EC $_{50}$ values: $42 \mu \mathrm{g} / \mathrm{mL}$ (DPPH scavenging activity), $41 \mu \mathrm{g} / \mathrm{mL}$ (reducing power), $18 \mu \mathrm{g} / \mathrm{mL}$ ( $\beta$-carotene bleaching inhibition) and $23 \mu \mathrm{g} / \mathrm{mL}$ (TBARS inhibition); Trolox IC 80 values: $22 \mu \mathrm{g} / \mathrm{mL}(60 \mathrm{~min})$ and $44.9 \mu \mathrm{g} / \mathrm{mL}(120 \mathrm{~min})$. A Student's $t$-test was used to determine the significant difference between two different samples, with $\alpha=0.05: \mathrm{p}<.001$ means a significant difference between the samples.

values than the corresponding pulp extract, except for its $\beta$-carotene bleaching inhibition activity (Table 5). Our results corroborate literature data, as several previous studies have demonstrated that figs' peel extracts display more pronounced antioxidant capacities than their correspondent pulp extract (Solomon et al., 2006; Oliveira et al., 2009; Ammar et al., 2015; Ajmal et al., 2016; Harzallah et al., 2016; Hoxha \& Kongoli, 2016; Maghsoudlou et al., 2017).

Maghsoudlou et al. (2017) found less expressive results than ours when assessing the antioxidant capacities of peel and pulp extracts of a green fig variety grown in Iran via DPPH assay $\left(\mathrm{IC}_{50}\right.$ values of 3.45 and $4.39 \mathrm{mg} / \mathrm{mL}$ for peel and pulp, respectively). However, when using the reducing power assay, the authors $\mathrm{IC}_{50}$ values were very similar to ours (4.62 and $4.44 \mathrm{mg} / \mathrm{mL}$ for peel and pulp, respectively). Harzallah et al. (2016) verified better antioxidant capacity values via reducing power method when analyzing different parts of a Tunisian green fig variety, with $\mathrm{IC}_{50}$ values of 0.5 and $2 \mathrm{mg} / \mathrm{mL}$ for peel and pulp, respectively. However, their antioxidant capacity values verified by the DPPH method were less expressive $\left(\mathrm{IC}_{50}=26.7 \mathrm{mg} / \mathrm{mL}\right.$ for the peel; $\mathrm{IC}_{50}=10.59 \mathrm{mg} / \mathrm{mL}$ for the pulp). Bachir Bey et al. (2017) assessed the capacities of whole figs from three fig varieties from Algeria in preventing $\beta$-carotene oxidation and reported an average antioxidant activity of $24 \%$.

Our antioxidant capacity values measured by the TBARS method were considerably better than the ones verified by Viuda-Martos et al. (2015) in their study on the antioxidant properties of fig peel and pulp powders obtained from discarded fruits. The authors found IC $_{50}$ values of $7.19-11.45 \mathrm{mg} / \mathrm{mL}$ for the peel powders and of $17.13-19.42$ for the pulp powders. For both assays (TBARS and OxHLIA), we used Trolox as the positive control; as expected, it displayed superior erythrocyteprotection capacity as well as inhibition of thiobarbituric acid reactive substances than the tested fig extracts.

The $F$. carica fruits' antioxidant capacities have been highly correlated with their amount of phenolic components (Arvaniti et al., 2019). Rutin (quercetin-3-O-rutinoside), the major individual phenolic in our peel sample, has demonstrated outstanding in vitro and in vivo antioxidant effects, among other bioativities (Gullón, Lú-Chau, Moreira, Lema, \& Eibes, 2017). For instance, this flavonoid has proven antioxidative effect when applied in meat products (Tang et al., 2019). Nonetheless, phenolic compounds are not the only phytochemical agents expressing antioxidant effects in fig fruits; this bioactivity could also be a result of the action of other molecules, such as triterpenoids (Wojdyło et al., 2016).

Sundry researchers have reported that fruits and vegetables act as barrier against cancer due to the presence of bioactive phytochemicals (Corrêa, Barros, et al., 2018). Phenolic matrices comprise an extremely rich source of phytochemicals, which present a multitude of health 
Table 6

Antibacterial potential of the Ficus carica peel and pulp hydroethanolic extracts.

\begin{tabular}{|c|c|c|c|c|c|c|c|c|c|c|}
\hline & \multicolumn{2}{|l|}{ Peel } & \multicolumn{2}{|l|}{ Pulp } & \multicolumn{2}{|c|}{ Ampicillin $(20 \mathrm{mg} / \mathrm{mL})$} & \multicolumn{2}{|c|}{ Imipenem $(1 \mathrm{mg} / \mathrm{mL})$} & \multicolumn{2}{|c|}{ Vancomycin ( $1 \mathrm{mg} / \mathrm{mL})$} \\
\hline & MIC & MBC & MIC & $\mathrm{MBC}$ & MIC & MBC & MIC & $\mathrm{MBC}$ & MIC & MBC \\
\hline \multicolumn{11}{|l|}{ Gram-negative bacteria } \\
\hline Escherichia coli & 5 & $>20$ & 5 & $>20$ & $<0.15$ & $<0.15$ & $<0.0078$ & $<0.0078$ & nt & nt \\
\hline Klebsiella pneumoniae & 20 & $>20$ & 20 & $>20$ & 10 & 20 & $<0.0078$ & $<0.0078$ & nt & nt \\
\hline Morganella morganii & 5 & $>20$ & 5 & $>20$ & 20 & $>20$ & $<0.0078$ & $<0.0078$ & nt & nt \\
\hline Proteus mirabilis & 20 & $>20$ & 20 & $>20$ & $<0.15$ & $<0.15$ & $<0.0078$ & $<0.0078$ & nt & nt \\
\hline $\begin{array}{l}\text { Pseudomonas aeruginosa } \\
\text { Gram-positive bacteria }\end{array}$ & $>20$ & $>20$ & 20 & $>20$ & $>20$ & $>20$ & 0.5 & 1 & nt & nt \\
\hline Enterococcus faecalis & $>20$ & $>20$ & $>20$ & $>20$ & $<0.15$ & $<0.15$ & nt & nt & $<0.0078$ & $<0.0078$ \\
\hline Listeria monocytogenes & $>20$ & $>20$ & $>20$ & $>20$ & $<0.15$ & $<0.15$ & $<0.0078$ & $<0.0078$ & nt & nt \\
\hline MRSA & 5 & $>20$ & 5 & $>20$ & $<0.15$ & $<0.15$ & nt & nt & $<0.0078$ & $<0.0078$ \\
\hline MSSA & 2.5 & $>20$ & 2.5 & $>20$ & $<0.15$ & $<0.15$ & nt & nt & 0.25 & 0.5 \\
\hline
\end{tabular}

MIC - minimum inhibitory concentration; MBC - minimum bactericidal concentrations.

MRSA - Methicillin-resistant Staphylococcus aureus; MSSA - Methicillin-sensitive Staphylococcus aureus.

n.t. - not tested.

benefits, including their ability to act as free radicals scavengers (Martins, Barros, \& Ferreira, 2016). Furthermore, these bioactive molecules possess the ability to strengthen the potential of other phytochemicals, to block side effects of some constituents and also to acquire other biological properties (when combined in whole matrices). Thus, despite of their occurrence in vestigial amounts, phytochemicals play a crucial role in preventing and treating diseases (Martins et al., 2016; Corrêa, Barros, et al., 2018).

\subsubsection{Antibacterial activity}

The $F$. carica hydroethanolic extracts' minimum inhibitory concentration (MIC) values for five Gram-negative and four Gram-positive bacteria are displayed in Table 6. Our peel and pulp extracts showed practically identical antibacterial capacities, being both more effective contra Gram-positive bacteria, especially methicillin-sensitive Staphylococcus aureus (MSSA) (MIC values of $2.5 \mathrm{mg} / \mathrm{mL}$ ). Likewise, both extracts inhibited the growth of methicillin-resistant Staphylococcus aureus (MRSA) as well as the Gram-negative bacteria Escherichia coli and Morganella morganii (all MIC values of $5 \mathrm{mg} / \mathrm{mL}$ ). Jeong et al. (2009) found lower MIC $(0.156-0.625 \mathrm{mg} / \mathrm{mL})$ and MBC $(0.313-0.625 \mathrm{mg} /$ $\mathrm{mL}$ ) values when evaluating the activity of a $F$. carica methanolic leaf extract against Gram-positive (Streptococcus gordonii, Streptococcus anginosus) and Gram-negative (Prevotella intermedia, Porphyromonas gingivalis) bacteria. Lazreg-Aref, Mars, Fekih, Aouni, and Said (2012) reported that the hexane extract of fig fruit latex had strong bactericidal effects against Gram-positive and Gram-negative bacteria, being very effective against Staphylococcus aureus ATCC 25923 (MIC $=19 \mu \mathrm{g} / \mathrm{mL}$ ). However, Oliveira et al. (2009) assessed the inhibitory effects of a $F$. carica aqueous extracts against Bacillus cereus, Staphylococcus epidermidis, S. aureus, E. coli, and Pseudomonas fluorescens using disc diffusion method, and found no antimicrobial activity. Nonetheless, we have not found a previous comparative study on the antimicrobial potential of fig fruit's peel and pulp.

Recently, Shahbazi (2018) developed and characterized several nanocomposite biofilms based on chitosan and carboxymethylcellulose and added with the essencial oil of Ziziphora clinopodioides Lam and/or with a methonolic extract of $F$. carica. According to the authors, the most pronounced antibacterial (inhibition zones ranging from 14 to $27 \mathrm{~mm}$ ) and antioxidant (DPPH scavenging activity of almost 40\%) actions were found for the chitosan-nanomontmorillonite-based film containing $2 \%$ of essential oil and $1 \%$ of fig extract.

The antibacterial potentials verified for our $F$. carica extracts likely relate to their major phenolic constituents, which are all molecules with proven biological activities, as well as to the possible synergistic action of these phytocomponents. Al-Shabib et al. (2017) highlighted the promissory potential of rutin as a natural biofilm control agent for food industry, as it effectively inhibited biofilms formed by drug resistant MRSA and $E$. coli. Indeed, a bioactive rutin isolated from the peels of the sweet orange [Citrus sinensis (L.) Osbeck] displayed anti-biofilm activity against multidrug-resistant $P$. aeruginosa (Deepika et al., 2018). Furthermore, Bajko, Kalinowska, Borowski, Siergiejczyk, and Lewandowski (2016) assessed the inhibitory effects of the chlorogenic acid (5-CQA) against E. coli, $S$. aureus, E. faecium, and P. aeruginosa, and reported MIC values ranging from 5 to $10 \mathrm{mg} / \mathrm{mL}$.

Our $F$. carica extracts displayed MIC values higher than 1.6 for all assessed bacteria (Table 6), which fits the classification of some authors for weak inhibitor profile (Corrêa, Peralta, et al., 2018); notwithstanding, the bacteria used in our assay are clinical isolated multi-resistant strains that present antibiotic resistance profiles quite higher to those of ATCC strains (Dias et al., 2016). Therefore, our data can be interpreted as evidence of important antibacterial potential.

\section{Conclusion}

Of millenary relevance, valued in our time as health and cultural foods, $F$. carica fruits are being prospected for scientists worldwide for the obtainment of high-added value bioproducts. Indeed, their peels present great potential as sources of natural food additives (antioxidants, preservatives, functionalizing ingredients) and nutraceuticals. To our best knowledge, this is the first study on the in-depth chemical characterization of the peel and pulp of a Portuguese green fig fruit cultivar, as well as on the evaluation of their antioxidant capacities using cell-based methods and antibacterial potentials. The information herein reported confirms that the fig peel is superior to the corresponding pulp as it relates to nutritional and phenolic profiles as well as biological activities, endorsing the urgency in valorising and exploiting this usually discarded agro industrial by-product.

\section{Declaration of Competing Interest}

None.

\section{Acknowledgments}

The authors are grateful to the Foundation for Science and Technology (FCT, Portugal) and FEDER under Programme PT2020 for financial support to CIMO (UID/AGR/00690/2019); national funding by FCT, P.I., through the institutional scientific employment programcontract for L. Barros, R. C. Calhelha, and M.I. Dias contracts, and Carla Pereira's contract though the celebration of program-contract foreseen in No. 4, 5 and 6 of article $23^{\circ}$ of Decree-Law No. 57/2016, of 29th August, amended by Law No. 57/2017, of 19th July; to FEDER-Interreg 
España-Portugal programme for financial support through the project 0377_Iberphenol_6_E; the European Regional Development Fund (ERDF) through the Regional Operational Program North 2020, within the scope of Project NORTE-01-0145-FEDER-023289: DeCodE.

\section{References}

Ajmal, M., Arshad, M. U., Saeed, F., Ahmed, T., Khan, A. U., Bader-ul-Ain, H., \& Suleria, H. A. R. (2016). Exploring the nutritional characteristics of different parts of fig in relation to hypoglycemic potential. Pakistan Journal of Life \& Social Sciences, 14, 115-122.

Alonso-Salces, R. M., Guillou, C., \& Berrueta, L. A. (2009). Liquid chromatography coupled with ultraviolet absorbance detection, electrospray ionization, collision induced dissociation and tandem mass spectrometry on a tripe quadrupole for the on-line characterization of polyphenols and methylxanthines in green coffee beans. Mass Spectrometry, 23, 363-383.

Al-Shabib, N. A., Husain, F. M., Ahmad, I., Khan, M. S., Khan, R. A., \& Khan, J. M. (2017). Rutin inhibits mono and multi-species biofilm formation by foodborne drug resistant Escherichia coli and Staphylococcus aureus. Food Control, 79, 325-332.

Amessis-Ouchemoukh, N., Ouchemoukh, S., Meziant, N., Idiri, Y., Hernanz, D., Stinco, C. M., ... Luis, J. (2017). Bioactive metabolites involved in the antioxidant, anticancer and anticalpain activities of Ficus carica L., Ceratonia siliqua L. and Quercus ilex L. extracts. Industrial Crops and Products, 95, 6-17.

Ammar, S., del Mar Contreras, M., Belguith-Hadrich, O., Segura-Carretero, A., \& Bouaziz, M. (2015). Assessment of the distribution of phenolic compounds and contribution to the antioxidant activity in Tunisian fig leaves, fruits, skins and pulps using mass spectrometry-based analysis. Food \& Function, 6, 3663-3677.

AOAC (2016). In W. George, \& J. Latimer (Eds.). Official Methods of Analysis of AOAC International - 20th Edition.(20th ed.). AOAC International. Retrieved from http:// www.techstreet.com/standards/official-methods-of-analysis-of-aoac-international20th-edition-2016? product id $=1937367$.

Arvaniti, O. S., Samaras, Y., Gatidou, G., Thomaidis, N. S., \& Stasinakis, A. S. (2019). Review on fresh and dried figs: Chemical analysis and occurrence of phytochemical compounds, antioxidant capacity and health effects. Food Research International, 119, 244-267.

Bachir Bey, M., Richard, G., Meziant, L., Fauconnier, M. L., \& Louaileche, H. (2017). Effects of sun-drying on physicochemical characteristics, phenolic composition and in vitro antioxidant activity of dark fig varieties. Journal of Food Processing and Preservation, 41, e13164.

Backes, E., Pereira, C., Barros, L., Prieto, M. A., Genena, A. K., Barreiro, M. F., \& Ferreira, I. C. (2018). Recovery of bioactive anthocyanin pigments from Ficus carica L. peel by heat, microwave, and ultrasound based extraction techniques. Food Research International, 113, 197-209.

Badgujar, S. B., Patel, V. V., Bandivdekar, A. H., \& Mahajan, R. T. (2014). Traditional uses, phytochemistry and pharmacology of Ficus carica: A review. Pharmaceutical Biology, 52, 1487-1503.

Bajko, E., Kalinowska, M., Borowski, P., Siergiejczyk, L., \& Lewandowski, W. (2016). 5-OCaffeoylquinic acid: A spectroscopic study and biological screening for antimicrobial activity. LWT- Food Science and Technology, 65, 471-479.

Barolo, M. I., Mostacero, N. R., \& López, S. N. (2014). Ficus carica L.(Moraceae): An ancient source of food and health. Food Chemistry, 164, 119-127.

Barros, L., Pereira, C., \& Ferreira, I. C. (2013). Optimized analysis of organic acids in edible mushrooms from Portugal by ultra fast liquid chromatography and photodiode array detection. Food Analytical Methods, 6, 309-316.

Barros, L., Pereira, E., Calhelha, R. C., Dueñas, M., Carvalho, A. M., Santos-Buelga, C., \& Ferreira, I. C. F. R. (2013). Bioactivity and chemical characterization in hydrophilic and lipophilic compounds of Chenopodium ambrosioides L. Journal of Functional Foods, 5, 1732-1740.

Bessada, S. M., Barreira, J. C., Barros, L., Ferreira, I. C., \& Oliveira, M. B. P. (2016) Phenolic profile and antioxidant activity of Coleostephus myconis (L.) Rchb. f.: An underexploited and highly disseminated species. Industrial Crops and Products, 89, $45-51$.

Buenrostro-Figueroa, J. J., Velázquez, M., Flores-Ortega, O., Ascacio-Valdés, J. A. Huerta-Ochoa, S., Aguilar, C. N., \& Prado-Barragán, L. A. (2017). Solid state fermentation of fig (Ficus carica L.) by-products using fungi to obtain phenolic compounds with antioxidant activity and qualitative evaluation of phenolics obtained. Process Biochemistry, 62, 16-23.

Clifford, M. N., Johnston, K. L., Knight, S., \& Kuhnert, N. (2003). Hierarchical scheme for LC-MSnidentification of chlorogenic acids. Journal of Agricultural and Food Chemistry, 51, 2900-2911.

Corrêa, R. C., Barros, L., Fernandes, Â., Sokovic, M., Bracht, A., Peralta, R. M., \& Ferreira, I. C. (2018). A natural food ingredient based on ergosterol: Optimization of the extraction from Agaricus blazei, evaluation of bioactive properties and incorporation in yogurts. Food \& Function, 9, 1465-1474.

Corrêa, R. C., Peralta, R. M., Haminiuk, C. W., Maciel, G. M., Bracht, A., \& Ferreira, I. C. (2018). New phytochemicals as potential human anti-aging compounds: Reality, promise, and challenges. Critical Reviews in Food Science and Nutrition, 58, 942-957.

Corrêa, R. C. G., de Souza, A. H. P., Calhelha, R. C., Barros, L., Glamoclija, J., Sokovic, M., Ferreira, I. C. (2015). Bioactive formulations prepared from fruiting bodies and submerged culture mycelia of the Brazilian edible mushroom Pleurotus ostreatoroseus Singer. Food \& Function, 6, 2155-2164.

Debib, A., Dueñas, M., Boumediene, M., Mothana, R. A., Latifa, A., \& Tir-Touil, M. A. (2016). Synergetic hepatoprotective effect of phenolic fractions obtained from Ficus carica dried fruit and extra virgin olive oil on CCL4-induced oxidative stress and hepatotoxicity in rats. Journal of Food Biochemistry, 40, 507-516.

Deepika, M. S., Thangam, R., Sakthidhasan, P., Arun, S., Sivasubramanian, S., \& Thirumurugan, R. (2018). Combined effect of a natural flavonoid rutin from Citrus sinensis and conventional antibiotic gentamicin on Pseudomonas aeruginosa biofilm formation. Food Control, 90, 282-294.

Del Caro, A., \& Piga, A. (2008). Polyphenol composition of peel and pulp of two Italian fresh fig fruits cultivars (Ficus carica L.). European Food Research and Technology, 226, 715-719.

Dias, M. I., Barros, L., Morales, P., Cámara, M., Alves, M. J., Oliveira, M. B. P., ... Ferreira, I. C. (2016). Wild Fragaria vesca L. fruits: A rich source of bioactive phytochemicals. Food \& Function, 7, 4523-4532.

Evans, B. C., Nelson, C. E., Shann, S. Y., Beavers, K. R., Kim, A. J., Li, H., ... Duvall, C. L. (2013). Ex vivo red blood cell hemolysis assay for the evaluation of pH-responsive endosomolytic agents for cytosolic delivery of biomacromolecular drugs. Journal of Visualized Experiments: JoVE, e50166.

FAO - Food and Agriculture Organization. FAOSTAT. (2017). http://www.fao.org/faostat/ en/\#data/QC (accessed 28 March 2019).

Ferreres, F., Gil-Izquierdo, A., Andrade, P. B., Valentao, P., \& Tomás-Barberán, F. A. (2007). Characterization of $C$-glycosyl flavones $O$-glycosylated by liquid chromatography-tandem mass spectrometry. Journal of Chromatography A, 1161, 214-223.

Ferreres, F., Gil-Izquierdo, A., Vinholes, J., Grosso, C., Valentão, P., \& Andrade, P. B. (2011). Approach to the study of C-glycosyl flavones acylated with aliphatic and aromatic acids form Spergularia rubra by high-performance liquid chromatographyphotodiode array detection/electrospray ionization multistage mass spectrometry. Rapid Communications in Mass Spectrometry, 25, 700-712.

Ferreres, F., Silva, B. M., Andrade, P. B., Seabra, R. M., \& Ferreira, M. A. (2003). Approach to the study of $C$-glycosyl flavones by ion trap HPLC-PAD-ESI/MS/MS: Application to seeds of quince (Cydonia oblonga). Phytochemical Analysis, 14, 352-390.

Gullón, B., Lú-Chau, T. A., Moreira, M. T., Lema, J. M., \& Eibes, G. (2017). Rutin: A review on extraction, identification and purification methods, biological activities and approaches to enhance its bioavailability. Trends in Food Science \& Technology, 67, 220-235.

Harzallah, A., Bhouri, A. M., Amri, Z., Soltana, H., \& Hammami, M. (2016). Phytochemical content and antioxidant activity of different fruit parts juices of three figs (Ficus carica L.) varieties grown in Tunisia. Industrial Crops and Products, 83, 255-267.

Hoxha, L., \& Kongoli, R. (2016). Evaluation of antioxidant potential of albanian fig varieties "kraps zi" and "kraps bardhe" cultivated in the region of Tirana. Journal of Hygienic Engineering and Design, 16, 70-74.

Jeong, Mi-Ran, Kim, Hye-Young, \& Cha, Jeong-Dan (2009). Antimicrobial Activity of Methanol Extract from Ficus carica Leaves Against Oral Bacteria. Journal of Bacteriology and Virology, 39, 97-102.

Kamiloglu, S., \& Capanoglu, E. (2015). Polyphenol content in figs (Ficus carica L.): Effect of sun-drying. International Journal of Food Properties, 18, 521-535.

Lazreg-Aref, H., Mars, M., Fekih, A., Aouni, M., \& Said, K. (2012). Chemical composition and antibacterial activity of a hexane extract of Tunisian caprifig latex from the unripe fruit of Ficus carica. Pharmaceutical Biology, 50, 407-412.

Lockowandt, L., Pinela, J., Roriz, C. L., Pereira, C., Abreu, R. M., Calhelha, R. C., Ferreira, I. C. (2019). Chemical features and bioactivities of cornflower (Centaurea cyanus L.) capitula: The blue flowers and the unexplored non-edible part. Industrial Crops and Products, 128, 496-503.

Maghsoudlou, E., Esmaeilzadeh Kenari, R., \& Raftani Amiri, Z. (2017). Evaluation of antioxidant activity of fig (Ficus carica) pulp and skin extract and its application in enhancing oxidative stability of canola oil. Journal of Food Processing and Preservation, 41, e13077.

Mahmoudi, S., Khali, M., Benkhaled, A., Boucetta, I., Dahmani, Y., Attallah, Z., \& Belbraouet, S. (2018). Fresh figs (Ficus carica L.): Pomological characteristics, nutritional value, and phytochemical properties. European Journal of Horticultural Science, 83, 104-113.

Marrelli, M., Menichini, F., Statti, G. A., Bonesi, M., Duez, P., Menichini, F., \& Conforti, F. (2012). Changes in the phenolic and lipophilic composition, in the enzyme inhibition and antiproliferative activity of Ficus carica L. cultivar Dottato fruits during maturation. Food and Chemical Toxicology, 50, 726-733.

Martins, N., Barros, L., \& Ferreira, I. C. (2016). In vivo antioxidant activity of phenolic compounds: Facts and gaps. Trends in Food Science \& Technology, 48, 1-12.

Meziant, L., Boutiche, M., Bey, M. B., Saci, F., \& Louaileche, H. (2018). Standardization of monomeric anthocyanins extraction from fig fruit peels (Ficus carica L.) using single factor methodology. Journal of food measurement \& characterization, 12, 2865-2873.

Mopuri, R., Ganjayi, M., Meriga, B., Koorbanally, N. A., \& Islam, M. S. (2018). The effects of Ficus carica on the activity of enzymes related to metabolic syndrome. Journal of Food and Drug Analysis, 26, 201-210.

Oliveira, A. P., Valentão, P., Pereira, J. A., Silva, B. M., Tavares, F., \& Andrade, P. B. (2009). Ficus carica L.: Metabolic and biological screening. Food and Chemical Toxicology, 47, 2841-2846.

Oliveira, A. P., Silva, L. R., Andrade, P. B., Valentão, P., Silva, B. M., Pereira, J. A., \& de Pinho, P. G. (2010). Determination of low molecular weight volatiles in Ficus carica using HS-SPME and GC/FID. Food Chemistry, 121, 1289-1295.

Pande, G., \& Akoh, C. C. (2010). Organic acids, antioxidant capacity, phenolic content and lipid characterisation of Georgia-grown underutilized fruit crops. Food Chemistry, 120, 1067-1075.

Pereira, C., Barros, L., Carvalho, A. M., \& Ferreira, I. C. (2013). Use of UFLC-PDA for the analysis of organic acids in thirty-five species of food and medicinal plants. Food Analytical Methods, 6, 1337-1344.

Pereira, C., López-Corrales, M., Serradilla, M. J., del Carmen Villalobos, M., Ruiz-Moyano, S., \& Martín, A. (2017). Influence of ripening stage on bioactive compounds and antioxidant activity in nine fig (Ficus carica L.) varieties grown in Extremadura, 
Spain. Journal of Food Composition and Analysis, 64, 203-212.

Pires, T. C., Dias, M. I., Barros, L., Alves, M. J., Oliveira, M. B. P., Santos-Buelga, C., \& Ferreira, I. C. (2018). Antioxidant and antimicrobial properties of dried Portuguese apple variety (Malus domestica Borkh. cv Bravo de Esmolfe). Food Chemistry, 240, 701-706.

Rodríguez-Solana, R., Galego, L. R., Pérez-Santín, E., \& Romano, A. (2018). Production method and varietal source influence the volatile profiles of spirits prepared from fig fruits (Ficus carica L.). European Food Research and Technology, 244, 2213-2229.

Russo, F., Caporaso, N., Paduano, A., \& Sacchi, R. (2014). Phenolic compounds in fresh and dried figs from Cilento (Italy), by considering breba crop and full crop, in comparison to Turkish and Greek dried figs. Journal of Food Science, 79, C1278-C1284.

Shahbazi, Y. (2018). Characterization of nanocomposite films based on chitosan and carboxymethylcellulose containing Ziziphora clinopodioides essential oil and methanolic Ficus carica extract. Journal of Food Processing and Preservation, 42, e13444.

Shi, Y., Mon, A. M., Zhang, Y., Fu, Y., Wang, C., Yang, X., \& Wang, Y. (2018). The genus Ficus (Moracea) used in diet: Its plant diversity, distribution, traditional uses and ethnopharmacological importance. Journal of Ethnopharmacology, 226, 185-196.

Solomon, A., Golubowicz, S., Yablowicz, Z., Grossman, S., Bergman, M., Gottlieb, H. E., ...
Flaishman, M. A. (2006). Antioxidant activities and anthocyanin content of fresh fruits of common fig (Ficus carica L.). Journal of Agricultural and Food Chemistry, 54, 7717-7723.

Takebayashi, J., Iwahashi, N., Ishimi, Y., \& Tai, A. (2012). Development of a simple 96well plate method for evaluation of antioxidant activity based on the oxidative haemolysis inhibition assay (OxHLIA). Food Chemistry, 134, 606-610.

Tang, R., Luo, J., Wang, W., Liu, D., Wang, G., \& Guo, X. (2019). Rutin's natural source Flos Sophorae as potential antioxidant and improver of fungal community in Chinese sausages. LWT- Food Science and Technology, 101, 435-443.

Vallejo, F., Marín, J. G., \& Tomás-Barberán, F. A. (2012). Phenolic compound content of fresh and dried figs (Ficus carica L.). Food Chemistry, 130, 485-492.

Viuda-Martos, M., Barber, X., Perez-Alvarez, J. A., \& Fernandez-Lopez, J. (2015)

Assessment of chemical, physico-chemical, techno-functional and antioxidant properties of fig (Ficus carica L.) powder co-products. Industrial Crops and Products, 69, 472-479.

Wojdyło, A., Nowicka, P., Carbonell-Barrachina, Á. A., \& Hernández, F. (2016). Phenolic compounds, antioxidant and antidiabetic activity of different cultivars of Ficus carica L. fruits. Journal of Functional Foods, 25, 421-432. 